\title{
Cytological diagnosis of lymphoma in serous effusions
}

\author{
AI SPRIGGS, RI VANHEGAN* \\ From the Laboratory of Clinical Cytology, Churchill Hospital, Oxford and the Department of \\ Histopathology, John Radcliffe Hospital, Oxford
}

SUMMARY A consecutive series is presented of 100 cases of malignant lymphoma in which a correlation could be made between the histological findings and the cytology of pleural or peritoneal fluid or both.

Using the Kiel classification, 80 cases could be given a histological label, while 20 remain unclassified.

In those cases in which lymphoma cells were identifiable in the serous fluid, their morphology was studied and was found in general to correlate well with the cell-type expected from the histology.

It is not claimed that the type of lymphoma can be reliably diagnosed from the cytology of pleural or peritoneal fluid, but an opinion can be provided as to the grade (high or low), and in some cases it is also possible to give an indication of the cell-type involved.

Pleural and peritoneal effusions are a well-known complication of the lymphomas, and a cytological examination of serous fluid often clarifies a diagnosis which would otherwise be obscure.

In Hodgkin's disease the cytological picture is most commonly non-specific, and a diagnosis can be made only occasionally by the finding of Sternberg-Reed cells and the associated cellular exudate. In the rest of the malignant lymphomas tumour cells may survive and multiply in the fluid, and in many cases an almost pure population of lymphoma cells is present in the pleural or peritoneal cavity.

In the past, many of these cases were labelled simply as "lymphosarcoma" or "reticulosarcoma," and with experience such a cytological diagnosis could be highly reliable. More recently, with increased understanding concerning the lymphocyte and the immune system, a more sophisticated classification has become possible. Even if nomenclature has not yet become standardised, pathologists working in this field can certainly understand each other, and the time seems ripe for a re-examination of lymphoma cells in serous fluids, in the light of the new knowledge.

In what follows, we shall use the Kiel classification as described by Lennert et al. ${ }^{12}$

* Present address: Department of Pathology, Princess Margaret Hospital, Swindon.

Accepted for publication 7 January 1981

\section{Material and methods}

Since 1949, stained smears of pleural and peritoneal deposits have all been mounted and permanently filed in the Laboratory of Clinical Cytology at Oxford. Since the preparations used (dried smears stained by May-Grünwald-Giemsa and mounted before use) show little deterioration over several decades, it is possible to review almost all the material over a 30 year period. Most of those seen since 1960 have also been wet-fixed and stained by Papanicolaou's method.

Similarly, embedded histological material is available over the same period, in the files of the Department of Histopathology, John Radcliffe Hospital, Oxford. The cases used were all of those for which adequate cytological and histological specimens were available; out of 140 cases, 100 provided material which could be compared. We estimate that pleural, peritoneal or pericardial fluid was submitted from about one out of every 20 cases of malignant lymphoma diagnosed in Oxford in the period 1949-79 (excluding acute leukaemia).

Since most of the smears were already stained and mounted, few further methods could be applied to these, but in all possible cases a periodic acid-Schiff stain was done, either on a destained smear or, if available, on a spare unstained one. In a few of the more recent cases an acid phosphatase stain was also performed, using the method of $\mathrm{Li}$ et al. ${ }^{3}$ 
In many cases, new sections were cut from the blocks, and (where appropriate) immunoperoxidase stains were done for light chains and for muramidase. Surface markers were only studied in very few cases. In 11 cases cell deposits were processed for electron microscopy.

Smears and sections were reviewed together by both the authors. The histological classification represents the opinion of RIV.

\section{Results}

The diagnoses were distributed as shown in Table 1.

As regards the non-Hodgkin's lymphomas, the distribution of those with effusions compared with all diagnosed cases can be seen in Table 2.

The cytological features found in the different categories were as follows:

Table 1 Diagnoses in 100 cases of malignant lymphoma

\begin{tabular}{lc}
\hline Type & No of cases \\
\hline Low-grade NHL & \\
Lymphocytic & 6 \\
Immunocytic & \\
(a) Lymphoplasmacytoid & 3 \\
(b) Plasmacytic & 2 \\
Centroblastic/centrocytic & 16 \\
Centrocytic & 9 \\
High-grade NHL & \\
Centroblastic & 8 \\
Lymphoblastic & \\
(a) non-T & 7 \\
(b) T & 5 \\
Immunoblastic & 9 \\
True histiocytic & 2 \\
Hodgkin's disease & \\
Lymphocytic predominance & 4 \\
Nodular sclerosing & 4 \\
Mixed cellularity & 3 \\
Lymphocyte depleted & 2 \\
Unclassified & 20 \\
Total & 100 \\
\hline
\end{tabular}

MALIGNANT LYMPHOMA, LYMPHOCYTIC

There are six cases in the series (other effusions have been seen complicating chronic lymphocytic leukaemia, but since there was no histological confirmation, they have been excluded). All but one of the six were recorded as leukaemic. Five were male and one female, and the youngest age was $58 \mathrm{yr}$.

All the effusions were pleural, and contained numerous lymphocytes. In two cases there were also abundant red cells. Apart from an apparently raised nucleo-cytoplasmic ratio, no morphological abnormality was observed in the lymphocytes in four cases. In two cases they showed the well known appearance of "cellules grumelées." 4 This expression refers to the markedly clumped chromatin, giving a clock-face or tessellated appearance (Fig. 1). We have not observed this in the lymphocytes in other conditions.

\section{MALIGNANT LYMPHOMA, LYMPHOPLASMA-} CYTOID (IMMUNOCYTIC)

There were three cases; a woman aged 68 yr presenting with lymphomatous involvement of the pleura; a woman aged $40 \mathrm{yr}$ with a tumour arising in the pelvis, peritoneal effusion, and involvement of kidneys, lungs and lymph nodes; and a man aged $71 \mathrm{yr}$ with a tumour of the ileum and widespread mesen teric and retroperitoneal involvement, and pleura and peritoneal effusions.

All three show a distinctive cytological picture with numerous lymphoplasmacytoid (LP) cells. In the case with a pelvic tumour these formed nearly $100 \%$ of the population in the ascitic fluid, but differed little from cells which can be seen in benign conditions, except that there was a deficit of the more mature forms. In the other woman, there was rather more maturation, and there were associated small lymphocytes (Plate Ia). In the man with lymphoma of the small bowel, LP cells accounted

Table 2 Distribution of non-Hodgkin's lymphoma

\begin{tabular}{|c|c|c|c|c|}
\hline Type & & $\begin{array}{l}\text { Present series with } \\
\text { effusions }-87 \text { cases } \\
\%\end{array}$ & $\begin{array}{l}\text { Surgical node biopsy (Lennert } 1978)^{2} \\
2215 \text { cases* }^{*} \\
\%\end{array}$ & $\begin{array}{l}\text { Oxford patients July } 75-\text { Feb } 79 \\
211 \text { cases } \\
\%\end{array}$ \\
\hline \multicolumn{5}{|l|}{ Low-grade } \\
\hline $\begin{array}{l}\text { Lymphocytic } \\
\text { Immunocytic }\end{array}$ & & $6 \cdot 9$ & $18 \cdot 6$ & $15 \cdot 6$ \\
\hline $\begin{array}{l}\text { (a) Lymphoplasmacytoid } \\
\text { (b) Plasmacytic }\end{array}$ & $\left.\begin{array}{l}3 \cdot 4 \\
2 \cdot 3\end{array}\right\}$ & $5 \cdot 7$ & $16 \cdot 7$ & $8 \cdot 9$ \\
\hline $\begin{array}{l}\text { Centroblastic/centrocytic } \\
\text { Centrocytic }\end{array}$ & $\left.\begin{array}{l}18 \cdot 4 \\
10 \cdot 3\end{array}\right\}$ & $28 \cdot 7$ & $29 \cdot 5$ & $36 \cdot 9$ \\
\hline \multicolumn{5}{|l|}{ High-grade } \\
\hline $\begin{array}{l}\text { Centroblastic } \\
\text { Lymphoblastic }\end{array}$ & & $9 \cdot 2$ & $5 \cdot 0$ & $3 \cdot 4$ \\
\hline $\begin{array}{l}\text { (a) non- } T \\
\text { (b) } \mathrm{T}\end{array}$ & $\left.\begin{array}{l}8 \cdot 0 \\
5 \cdot 7\end{array}\right\}$ & $13 \cdot 7$ & $11 \cdot 0$ & $4 \cdot 5$ \\
\hline $\begin{array}{l}\text { Immunoblastic } \\
\text { True histiocytic } \\
\text { Unclassified }\end{array}$ & & $\begin{array}{r}10 \cdot 3 \\
2 \cdot 3 \\
23 \cdot 0\end{array}$ & $\begin{array}{c}9 \cdot 3 \\
(\text { n.i. }) \\
9 \cdot 8\end{array}$ & $\begin{array}{r}10 \cdot 1 \\
5 \cdot 0 \\
15 \cdot 6\end{array}$ \\
\hline
\end{tabular}

*Derived from Lennert's Table 13." 


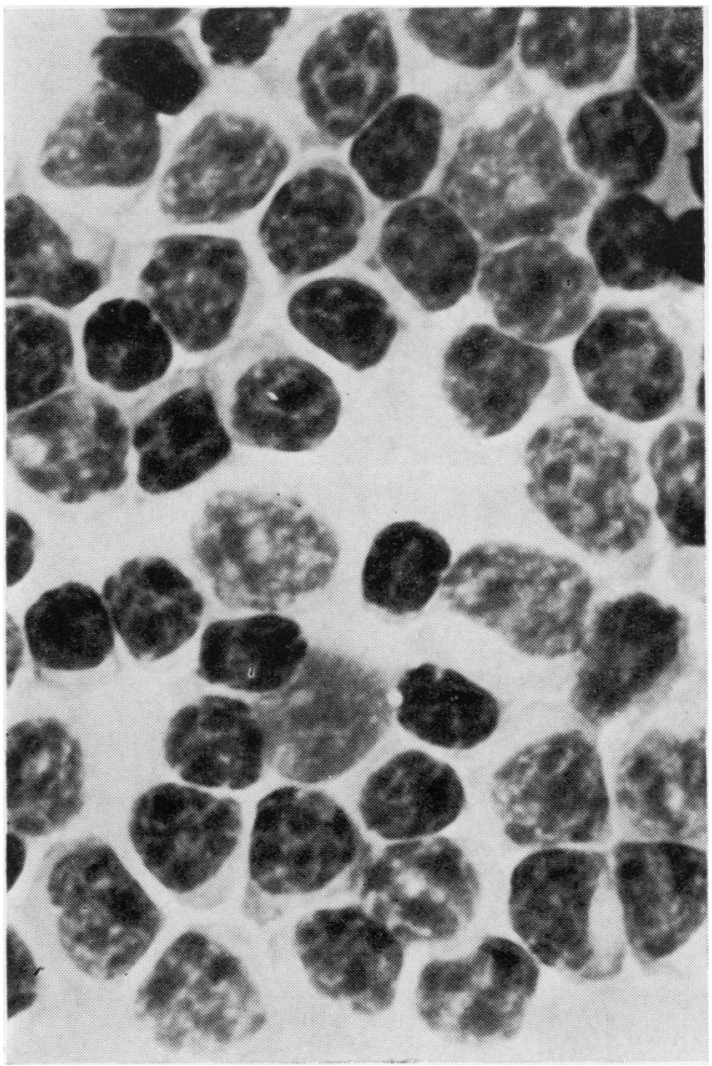

Fig. 1 Malignant lymphoma, lymphocytic. Cells from pleural fluid. Note the abnormally discrete blocks of chromatin. May-Grünwald-Giemsa $\times 1300$.

for only about $40 \%$ of the cells, and included some mature forms; these were not originally reported as being neoplastic, though "immature" forms were unusually numerous.

A feature which might be useful in diagnosis is that mitotic activity was very low in all three cases. This is in contrast to the behaviour of LP cells in benign effusions, where they usually show frequent mitotic figures (Plate Ib; also see Spriggs \& Boddington ${ }^{5}$ Fig. 20). Numerous LP cells were also found in pleural and peritoneal effusions of another case in our series, with a centrocytic lymphoma of the stomach; and here too the (presumably reactive) LP cells showed numerous mitoses.

\section{PLASMACYTOMA}

There were two cases of plasmacytoma with pleural effusion. In one of these, a woman of $45 \mathrm{yr}$ admitted for dialysis on account of myeloma kidney, the predominant cells in pleural fluid were myeloma cells (Fig. 2). In the other, a man of $70 \mathrm{yr}$ with known myelomatosis and an encysted pleural effusion, myeloma cells were found in small numbers among abundant red cells and other nucleated cells (including a few myelocytes and normoblasts); but the diagnosis could not have been made on cytological grounds.

MALIGNANT LYMPHOMA, CENTROBLASTIC/ CENTROCYTIC

As expected, the low grade follicle centre tumours were a common cause of effusions, exceeding those due to Hodgkin's disease. There were 16 in the series, seven men (aged 45-66 yr) and nine women (aged 32-73 yr). Twelve had pleural and three peritoneal effusions only, and one had both. One peritoneal and four pleural fluids were chylous.

In four cases no cells could be found which could be confidently identified as neoplastic centrocytes or centroblasts. In one of these, the fluid was full of cholesterol crystals, and the cells were unrecognisable. In the others the predominant cells were small lymphocytes, and one had many mesothelial cells, macrophages and eosinophils as well.

All but one of the remaining cases showed to a greater or lesser extent a picture which we have learnt to recognise, and which in typical form is characteristic of centroblastic/centrocytic lymphoma. The identifiable lymphoma cells did not account for a high proportion of the cell population; usually there was a predominance of small lymphocytes, and in six cases there were also substantial numbers of mesothelial cells and macrophages. Eosinophils were not a feature.

The usual picture is as follows, as seen in Romanowsky-stained smears (Plate Ic, d). Besides normallooking small lymphocytes, there are slightly larger ones (10-14 $\mu \mathrm{m}$ diameter) with condensed nuclear chromatin, not fine as in a "blast cell," and nucleoli are invisible or quite small. The nuclear outline is irregular or cleft. The cytoplasm forms a very narrow rim, and is no more basophilic than that of an ordinary small lymphocyte.

These smaller forms correspond to the neoplastic germinal centre cells illustrated by Moeschlin, ${ }^{6}$ or to the "haematogones" of Rosenthal, ${ }^{7}$ and are evidently neoplastic centrocytes. ${ }^{8}$ Their recognition depends on the quality of the smear, and since the lymphocytes of effusions are in any case quite variable, they are seldom obvious enough to be diagnostic by themselves. The presence in addition of larger forms, with diameters up to $20 \mu \mathrm{m}$, but with similar nuclear and cytoplasmic features, makes the diagnosis highly probable. All these cells may show slight positive granulation with PAS.

The cells described above are not the same as the normal centrocytes seen in imprints from reactive 

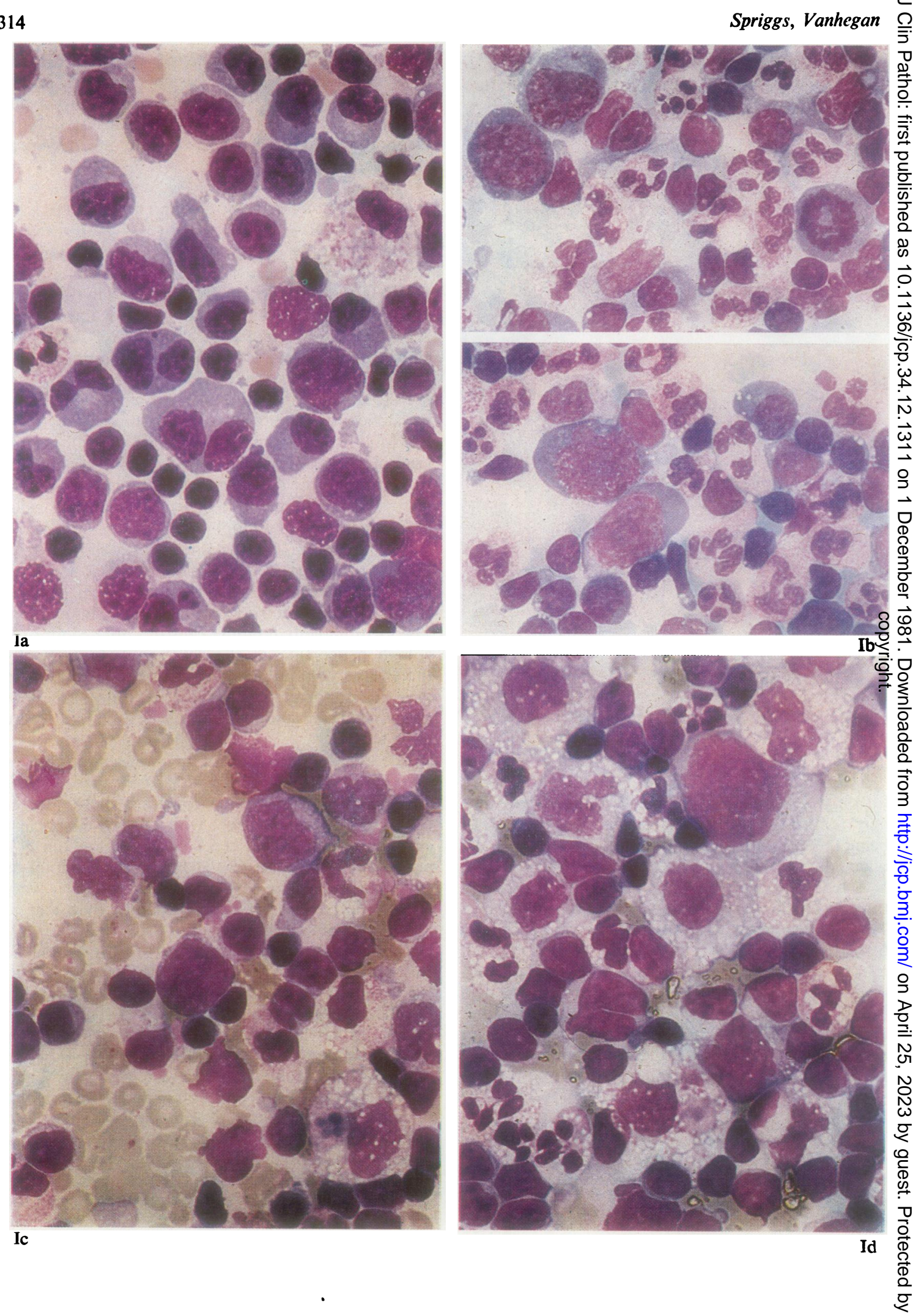
Plate Ia Malignant lymphoma, lymphoplasn:acytoid (immunocytic). Cells from pleural effusion. A mixed population of lymphocytes and lymphoplasmacytoid (LP) cells, some of the larger ones almost classifiable as immunoblasts. May-Grünwald-Giemsa $\times 750$.

Plate Ib Benign lymphoplasmacytoid reaction in pleural fluid, in a case of squamous carcinoma of the lung. No malignant cells were seen. The two largest cells in lower frame are immunoblasts. May-Grünwald-Giemsa $\times 750$.

Plate Ic Malignant lymphoma, centroblastic/centrocytic. Cells in peritoneal fluid. Some of the sn:all "lymphocytes" have cleft nuclei and reduced cytoplasm. Two large lymphoid cells are clearly neoplastic; one has extremely reduced cytoplasm, and both show large irregular nucleoli; they may be considered intermediate between centroblast and centrocyte. May-Grünwald-Giemsa $\times$ 750.

Plate Id Malignant lymphoma, centroblastic/centrocytic. Cells in pleural fluid. The small lymphocytes are indistinguishable from normal. Larger cells with identical nuclear chromatin have irregularly cleft nuclei and little cytoplasm (neoplastic centrocytes). The largest cell is a centroblast. Macrophages and neutrophils also present. May-Grünwald-Giemsa $\times 750$.

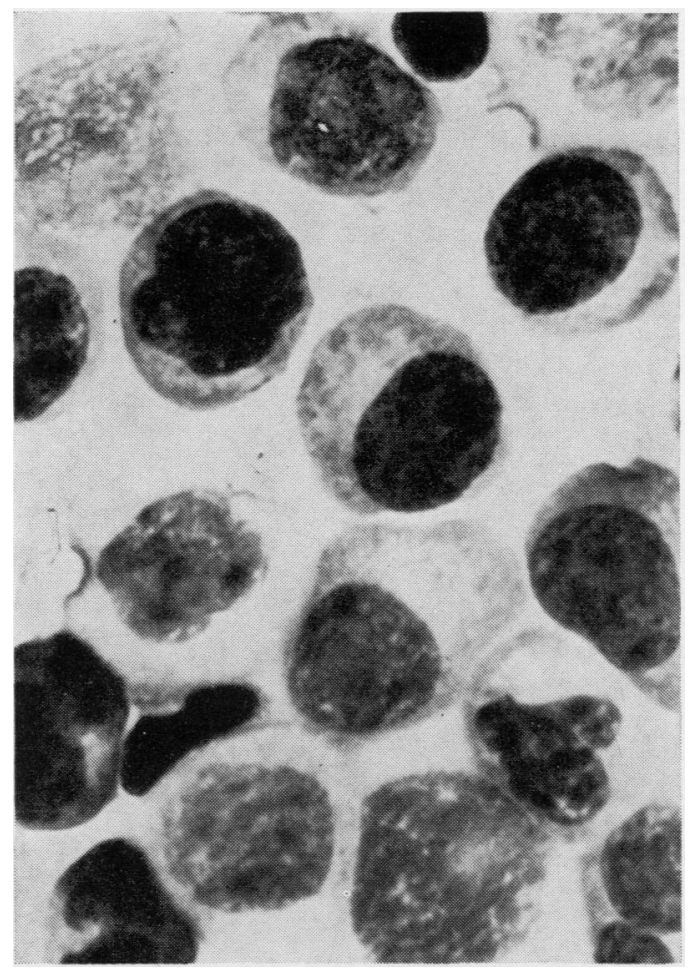

Fig. 2 Malignant lymphoma, plasmacytic. Pleural fluid, in which a high proportion of the cells present were myeloma cells. May-Grünwald-Giemsa $\times 1300$. lymph nodes. We have called them "neoplastic centrocytes" to include the small "haematogones" and the larger cells sometimes called "lymphosarcoma cells" in the context of "lymphosarcoma-cell leukaemia."

Neoplastic centroblasts have also been seen in these smears, but they were only frequent in one case. They differed from large neoplastic centrocytes in having finer chromatin with obvious nucleoli, and some of them had more profuse cytoplasm (Plate Id).

One case differed clearly from the rest; a woman aged $35 \mathrm{yr}$, who two years before had had lymph node biopsies showing centroblastic/centrocytic lymphoma. The disease evidently entered a more aggressive phase, and a rapidly developing peritoneal effusion showed a monotonous picture of lymphoma cells, many of them in varying stages of necrosis. They mostly measured $14 \mu \mathrm{m}$ or less in diameter, and the nuclei were slightly irregular or notched. The cytoplasm was scanty and pale staining, and with PAS showed fine granular positivity. These cells can be accepted as malignant centrocytes, and presumably the ultimate diagnosis would have been centrocytic lymphoma, but no biopsy was taken at that stage. A concomitant pleural effusion contained small numbers of the same cells, but associated with numerous mesothelial cells, macrophages, neutrophils and lymphocytes.

In five cases a remarkable cytophagocytic phenomenon was seen. Compound structures, which at low magnification looked like multinucleate giant cells, in fact consisted of lymphoma cells (or lymphocytes) crammed into the cytoplasm of another cell, presumably a macrophage. (This phenomenon has been described previously from serous effusions by Murad $^{9}$ and is illustrated by Hajdu \& Hajdu $^{10}$.) It is common for macrophages in effusions to contain the remains of digested cells, but in these lymphoma cases many, or most, of the ingested lymphoid cells appear well preserved.

There are various descriptions in the experimental literature of the presence, real or apparent, of living lymphocytes within the cytoplasm of cultured cells, ${ }^{11-13}$ and where macrophages are concerned it seems likely that some interaction of immunological significance is taking place. Histiocytes full of lymphocytes are also a distinctive feature of the lymph nodes in the benign condition known as "sinus histiocytosis with massive lymphadenopathy."14

Besides these four cases of centroblastic/centrocytic lymphoma, the same phenomenon was seen in serous fluid from one case of diffuse centrocytic lymphoma (Fig. 3, \& Plate IIa), one of $\mathrm{T}$ lymphoblastic lymphoma, and one of an unclassified lymphoma (possibly Lennert's lymphoepithelioid cell 

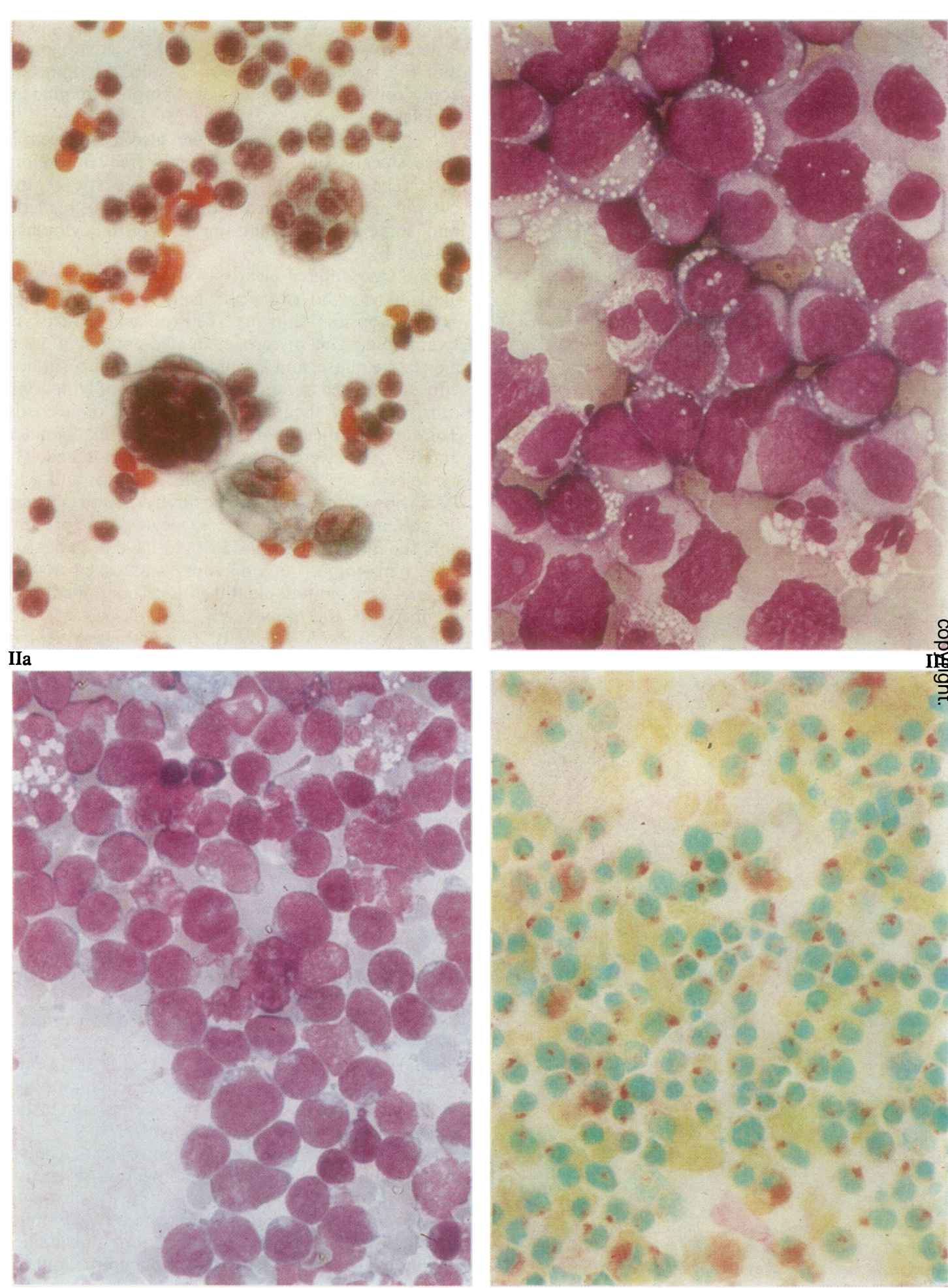

II $\stackrel{0}{\circ}$

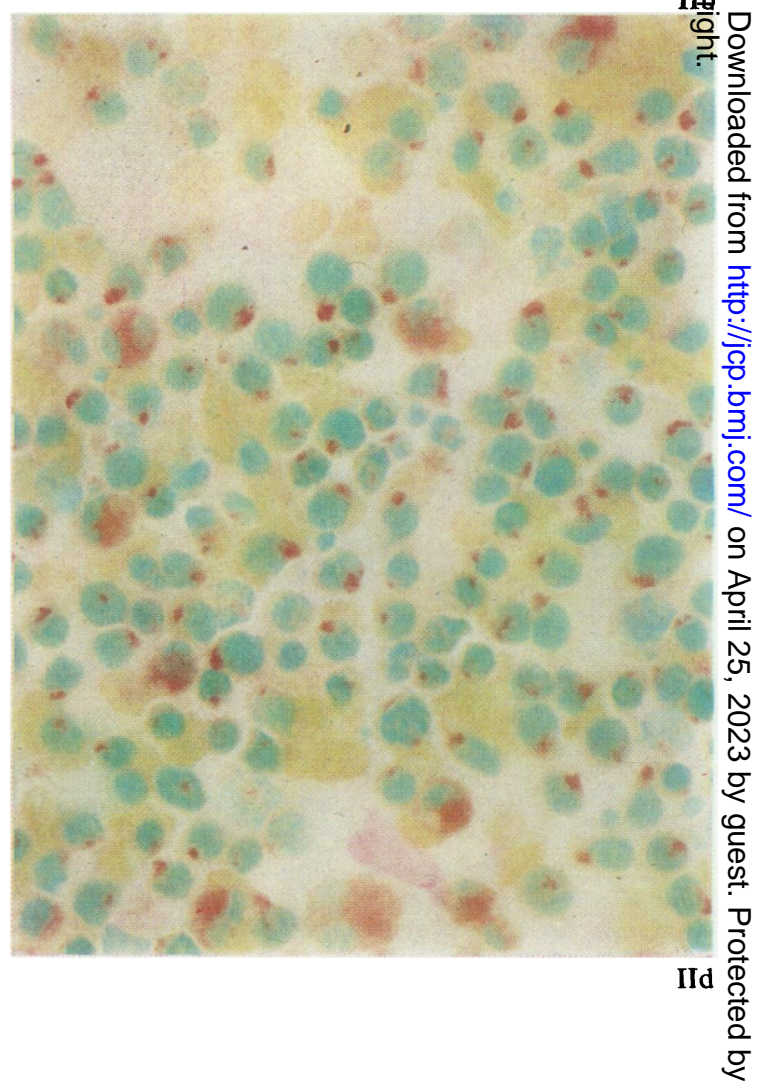




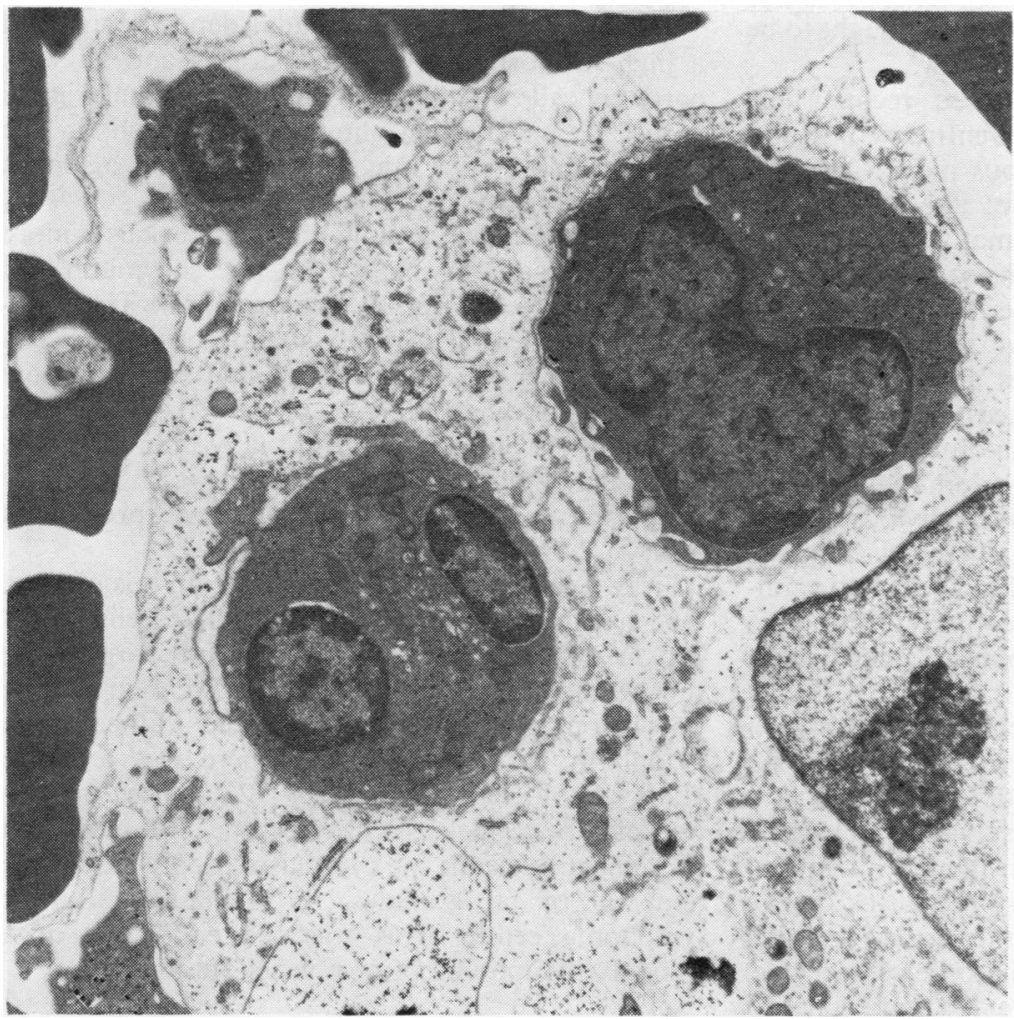

Fig. 3 Malignant lymphoma, centrocytic. Electron micrograph showing part of a macrophage with ingested lymphoid cells. Compare Plate IIa $\times 9600$.

lymphoma). We have not observed it in any serous effusion apart from lymphoma and it is therefore of positive diagnostic usefulness. The above findings show that it is not specific for any single type, even if it occurs most commonly in follicle centre lymphomas.

Plate IIa Malignant lymphoma, centrocytic. This pleural fluid contained many compound structures consisting of lymphoid cells within macrophage cytoplasm. Same case as Fig. 3. Papanicolaou $\times 750$.

Plate IIb Malignant lymphoma, centroblastic. Pleural fuid deposit showing a high proportion of malignant centroblasts. This was the terminal stage of a centroblastic-centrocytic lymphoma. May-GrünwaldGiemsa $\times 750$.

Plate IIc T lymphoblastic lymphoma. The cells in pleural fluid have the usual features of lymphoblasts as seen in the blood in acute lymphoblastic leukaemia. Their "convoluted" nuclei are packaged into more or less spherical shape by the thin skin of cytoplasm. May-Grünwald-Giemsa $\times 750$.

Plate IId T lymphoblastic lymphoma. Same material as IIc, stained for acid phosphatase. The cells with diffuse cytoplasmic staining are eosinophil granulocytes. The lymphoma cells show a localised positive reaction. May-Grünwald-Giemsa $\times 750$.
MALIGNANT LYMPHOMA, CENTROCYTIC

Although this is included in Lennert's ${ }^{2}$ classification as a low grade lymphoma, he admits that the centrocytes are "somewhat more anaplastic" than in centroblastic/centrocytic lymphoma, and the prognosis poorer; its leukaemic variant is the so-called "lymphosarcoma cell leukaemia."

There were nine cases in our series, six women (37-85 yr) and three men (59-78 yr). Six had pleural effusion alone (two of them chylous), two had ascites alone (one chylous), and one had pleural and peritoneal effusions.

Judging by the cytology of the fluids they are a heterogeneous group, perhaps depending on whether or not the serosal surface has been invaded by neoplastic cells.

In four cases there was nothing cytologically distinctive of lymphoma. Three of these showed numerous lymphocytes, and the fourth, a woman of $31 \mathrm{yr}$ with a lymphoma of the stomach, had in addition large numbers of LP cells in both pleural and peritoneal fluid. These were of normal morphology and had a high mitotic index-a finding which is seen in benign effusions where immunocytes are numerous, but was not seen in the three genuine cases of immunocytic lymphoma. 
Although at the time (1954) they were thought to be lymphoma cells, we do not think so now.

The remaining five cases showed recognisable lymphoma cells, but they were not entirely consistent in type. In one of them, a chylous pleural effusion developing in a 59-year-old man, almost the only nucleated cells found were haematogone-like cells hardly larger than normal lymphocytes-that is, about $10 \mu \mathrm{m}$ in diameter. The same cells were abundant in his bone marrow. In another case there were ordinary lymphocytes about $6-8 \mu \mathrm{m}$ in diameter, and lymphoma cells measuring 10-14 $\mu \mathrm{m}$, of the type described above. In another there was a similar picture, but with the addition of many normal LP cells. In another with chylous ascites from a lymphoma of the bowel, there was a mixed cellular picture including LP cells, and small numbers of cells similar to lymphocytes but about 16 $\mu \mathrm{m}$ across, presumed to be neoplastic centrocytes.

The last case was mentioned before in connection with the phenomenon of phagocytosis of lymphoma cells in centroblastic/centrocytic lymphoma. A woman aged $85 \mathrm{yr}$ had an illness with a course of only four months, with a mass in the left hilum and hepatosplenomegaly. At necropsy there was diffuse infiltration of lymph nodes and other organs by small lymphoma cells thought probably to be centrocytes. The pleural fluid showed a picture like that described above for centroblastic/centrocytic lymphoma; there were normal lymphocytes, macrophages and mesothelial cells, neoplastic centrocytes varying in size from "haematogones" $8 \mu \mathrm{m}$ across up to forms measuring $20 \mu \mathrm{m}$; and there were numerous clusters of lymphoma cells or lymphocytes, or both, packaged within the cytoplasm of a macrophage as described above (Plate IIa and Fig. 3).

From this series of centrocytic lymphomas it would appear that a diagnosis of lymphoma from pleural fluid cytology is possible in some but not all cases, and that the cells could probably be recognised as of follicle centre origin; but evidently the subclassification into "centrocytic" lymphoma of intermediate aggressiveness, as distinct from the lowgrade "centroblastic/centrocytic" lymphoma, would be unreliable on cytological grounds, except perhaps in the leukaemic form.

MALIGNANT LYMPHOMA, CENTROBLASTIC This high-grade lymphoma is often the end-stage of a chronic low-grade lymphoma of centroblastic/ centrocytic type. It is represented by eight cases in this series - two men (44 and $69 \mathrm{yr}$ ) and six women (36 to $72 \mathrm{yr}$ ). Seven had pleural effusions only (one chylous), and one had chylous peritoneal and pleural effusions.
In all of these cases the cellular deposit contained a high proportion of neoplastic cells and all were correctly called malignant lymphoma in the original report. Four of them showed cells which, in the light of this study, might be recognised again as neoplastic centroblasts (Plate IIb).

The cell diameter is $18-30 \mu \mathrm{m}$. The nucleus is more or less irregular in shape, with fine chromatin and distinct nucleoli (usually two or more). The cytoplasm is moderately or only slightly basophilic, less than that of most immunoblasts, and does not show the "Hof" or pale Golgi area at the cell centre which distinguishes plasma cells and many immunoblasts. Small lymphoid cells $(12 \mu \mathrm{m}$ diam) which could be neoplastic centrocytes were sometimes present as well.

In two cases there was variation from this picture. One had mainly small lymphocyte-like cells, 10-18 $\mu \mathrm{m}$ in diameter but mostly $12-14 \mu \mathrm{m}$, resembling the cells of centrocytic lymphoma except in the possession of visible nucleoli and rather more cytoplasm. In the other case there was a "pure culture" of cells measuring 12-22 $\mu \mathrm{m}$, mostly occupied by a nucleus with very fine chromatin and prominent nucleoli; the cytoplasm deeply basophilic and full of fat granules, as in classical Burkitt lymphoma cells. ${ }^{15}$ This was the end stage of follicular lymphoma of nine years duration.

MALIGNANT LYMPHOMA, LYMPHOBLASTIC (NON-T)

This category includes seven cases, four women (57-73 yr) and three men aged 28,42 and $76 \mathrm{yr}$. Five had pleural effusions and three peritoneal. Two of these patients had acute lymphoblastic leukaemia, but the rest were not recorded as leukaemic.

In all cases the lymphoma cells accounted for a high proportion of the nucleated cells present. In two cases, both with peritoneal effusions (one chylous), a large number of the cells were necrotic, although no cytotoxic treatment had been given. This phenomenon was also observed in the immunoblastic lymphomas.

In six of the cases the lymphoma cells were small, 10-16 $\mu \mathrm{m}$ in diameter, accounted for almost entirely by nucleus, the cytoplasm being extremely reduced. Usually the nucleus had clefts or folds; the chromatin was fine, but in some cases less fine than in classical "blast cells." Nucleoli were only visible in two cases from this group.

One case differed from the rest in having larger cells, mostly $14-20 \mu \mathrm{m}$ in diameter, with a coarser nuclear chromatin, prominent nucleoli, and basophilic cytoplasm. In these features they resembled immunocytes or small immunoblasts. Histologically also, there were areas which looked immunocytic 
rather than lymphoblastic, and this may be a B cell neoplasm of intermediate type.

In all cases the cytoplasm was PAS negative.

MALIGNANT LYMPHOMA, T LYMPHOBLASTIC Five cases with pleural effusions can be assigned to this group. One was a man of $68 \mathrm{yr}$ with a tumour arising in the nasopharynx, one a woman of $24 \mathrm{yr}$ with pleural effusion as the main and presenting symptom, and three were women, aged 13, 18 and $29 \mathrm{yr}$, with mediastinal lymphomas. Four of these cases had marrow involvement; one of these is alive five years after beginning successful chemotherapy and has borne a healthy child.

In two cases the great majority of the nucleated cells present were lymphoma cells but in one there were scattered eosinophils. In a third case lymphoblasts were mixed with smaller numbers of neutrophils and macrophages. In a fourth, the survivor, lymphoblasts were scattered among much larger numbers of lymphocytes, macrophages, mesothelial cells and neutrophils. The fifth case, the girl of $13 \mathrm{yr}$, showed to a striking degree the phenomenon of lymphophagocytosis, many of the ingested lymphoid cells being in various stages of digestion.

In all cases the lymphoma cells were of similar type. The diameter ranged from 8 to $20 \mu \mathrm{m}$, accounted for almost entirely by nucleus, the cytoplasm existing as a very narrow skin visible mainly at points where the nucleus was indented. The chromatin was usually less fine than in a classical "lymphoblast" and nucleoli were invisible (Plate IIc). The "convoluted" shape of the nuclei was not obvious in air-dried smears, but could be seen in wet-fixed Papanicolaou smears; nevertheless lymphoma cells of other types so often have irregularly shaped nuclei that this feature is quite non-specific.

Acid phosphatase stain was done in two of the five cases, and showed the classical strongly positive spot (Plate IId). ${ }^{16} 17$

MALIGNANT LYMPHOMA, IMMUNOBLASTIC Nine cases were placed in this category-two men (49 and $54 \mathrm{yr}$ ), and seven women (41 to $68 \mathrm{yr}$ ). Six had pleural effusions and three peritoneal; none of them was chylous.

Two of these effusions presented a mixed cytoogical picture with lymphocytes, neutrophils, macrophages, mesothelial cells and in one case eosinophils, but no neoplastic cells were recognised. In one of these there were frequent LP cells but they appeared normal.

The remaining seven cases all had recognisable malignant cells. In three they were outnumbered by other cell types, while in four they formed a very high percentage of the cells present (Plate IIIa). In three of the latter there were numerous dead tumour cells. This picture, with a few surviving lymphoma cells among abundant necrotic ones, is very characteristic and has been previously described. 5101819 In one of these cases immunoblastic lymphoma supervened after two years of chemotherapy for myelomatosis (Plate IIIb).

Neoplastic immunoblasts in the above cases had certain features in common as follows:

Most cells measure $15-22 \mu \mathrm{m}$ in diameter. The nucleus has a fine chromatin pattern. Its outline is usually rounded but can be of very irregular shape, and it contains one or more large irregular nucleoli. The cytoplasm varies greatly in amount but is nearly always basophilic, sometimes intensely so, and may be full of fat granules. A rather distinctive feature is the pale Golgi area at the cell centre, and in forms with well developed cytoplasm this causes a distinct resemblance to an "immature" plasma cell (Plate IIIa). In two cases this feature was not present, and the distinction from centroblastic lymphoma was not possible on cytological grounds. PAS was variable, sometimes negative but in some cases quite strongly granular positive.

It must be emphasised that each of these highly malignant neoplasms is unique, and the appearance of the cells is distinctive for that case only. Resemblances between the cells of different cases are much vaguer and there is no "typical" neoplastic immunoblast.

\section{MALIGNANT HISTIOCYTOSIS}

There were two cases of true histiocytic neoplasm. One was a woman of 77 yr who developed purpura, developing into multiple cutaneous nodules; within a few months she developed pleural effusion, and died three months later. The other was a man of $27 \mathrm{yr}$ with dysphagia and Horner's syndrome, due to lymphadenopathy of the neck and mediastinum. He developed a massive bloody pleural effusion and died soon after.

In the first case, the pleural fluid contained red cells with many neoplastic cells and a few lymphocytes. The neoplastic cells ranged from monoblastlike forms $22-26 \mu \mathrm{m}$ across, occupied mainly by nucleus, to macrophage-like types with profuse foamy cytoplasm, measuring $30-40 \mu \mathrm{m}$ in diameter. The former had multiple irregular nucleoli, usually indistinct. Some of them contained inclusions derived from cell debris, and occasionally a recognisable leucocyte, but ingested red cells were rarely seen (Plate IIIc). Acid phosphatase stain was diffusely positive.

In the second case, besides spherocytic red cells there were scattered malignant cells, most of them necrotic. They varied greatly in size, shape and 
1320

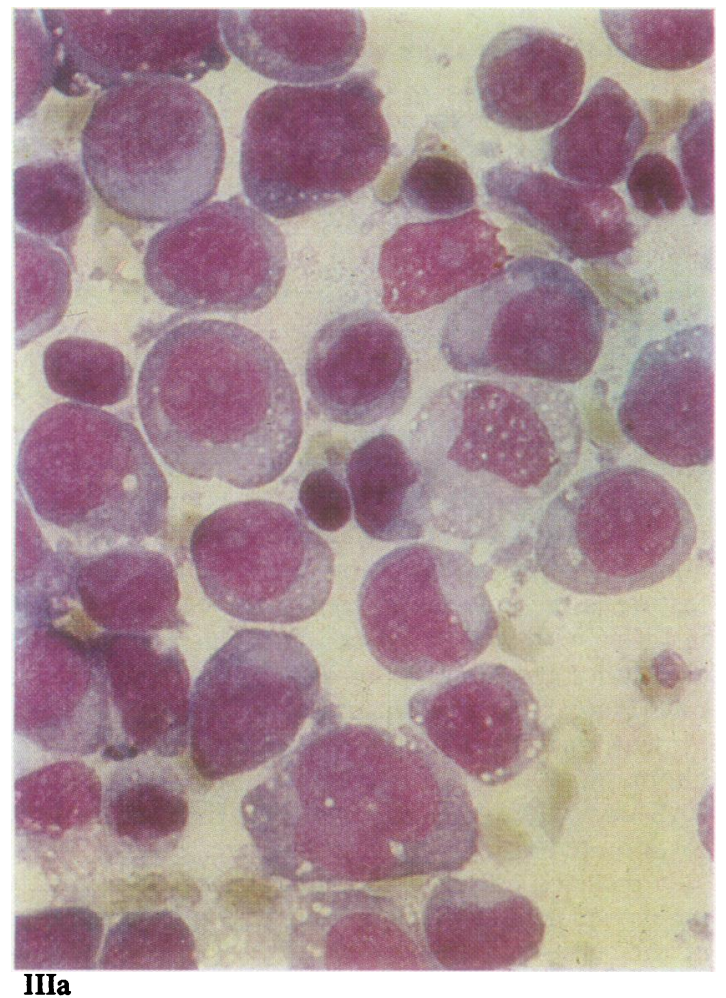

IIIa

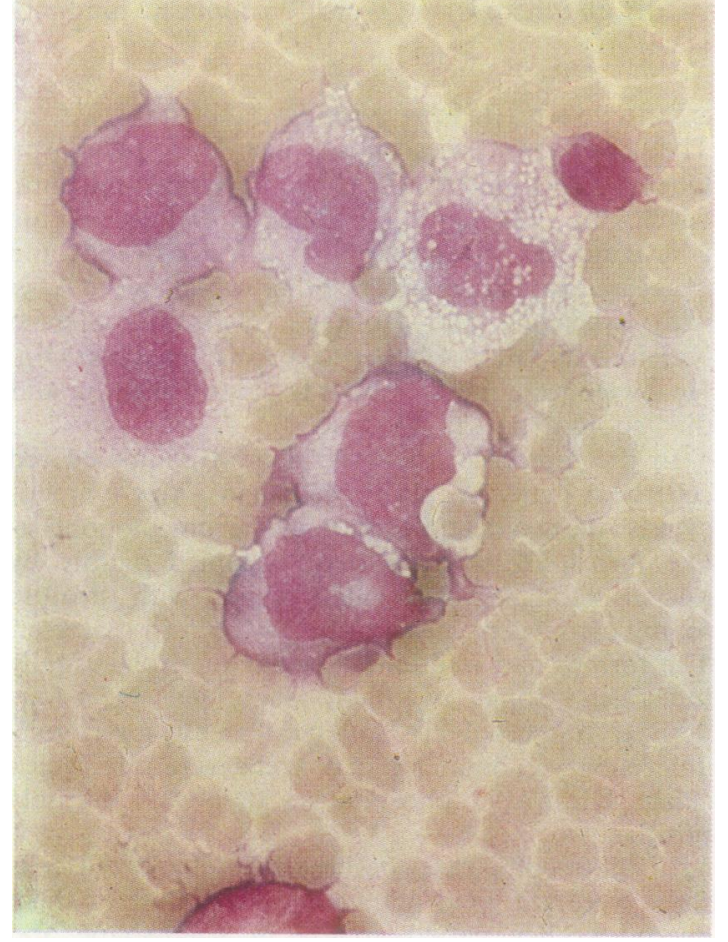

IIIc
Spriggs, Vanhegan
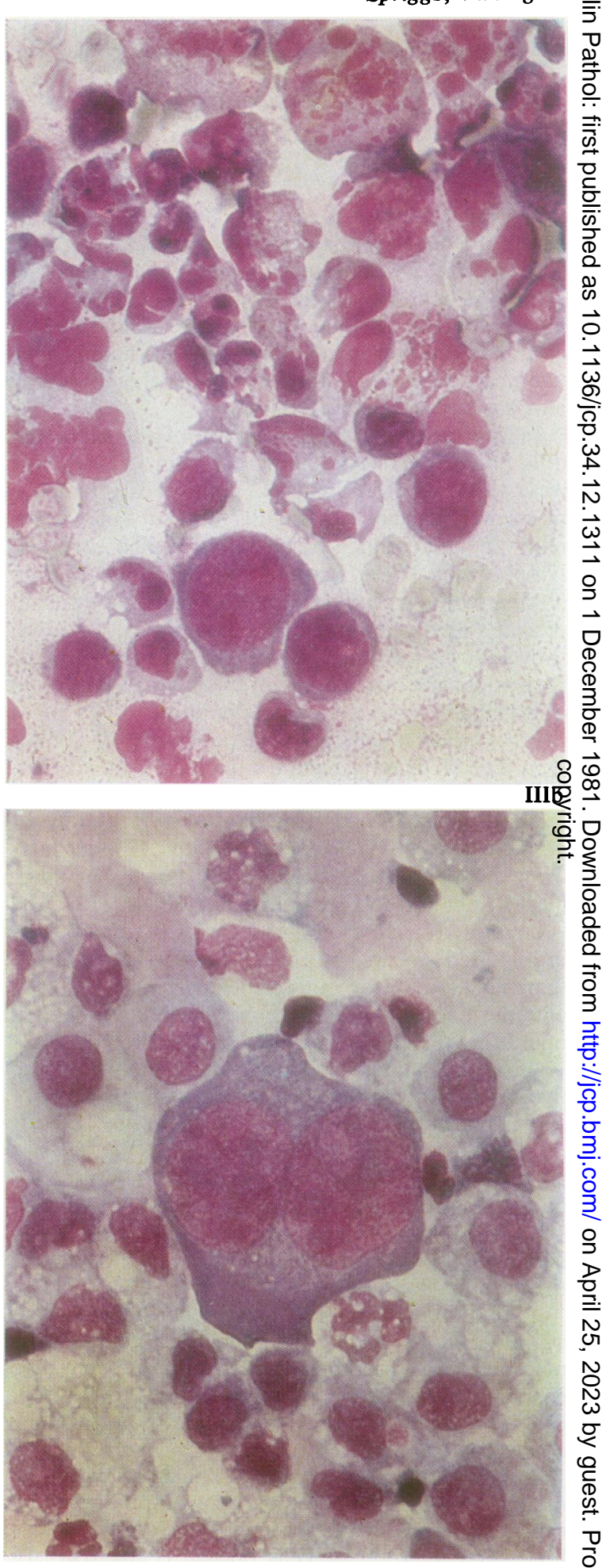
Plate IIIa Malignant lymphoma, immunoblastic. Cells in pleural fluid. Note the one or two large nucleoli, the large pale Golgi area in an otherwise basophilic cytoplasm, and the presence of forms with eccentric nuclei. May-Grünwald-Giemsa $\times 750$.

Plate IIIb Malignant lymphoma, immunoblastic. In this case the majority of the cells are dead, with karyorrhexis and pyknosis. This appearance is very characteristic of high-grade lymphoma. $\times 750$.

Plate IIIc Malignant histiocytosis. This pleural fluid shows immature-looking histiocytes together with related forms containing phagocytic vacuoles. MayGrünwald-Giemsa $\times 750$.

Plate IIId Lymphocyte-depleted Hodgkin's disease. The pleural fluid contained a mixture of benign cells as well as numerous cells of Sternberg-Reed type as shown here at centre. May-Grünwald-Giemsa $\times 750$.

nucleo-cytoplasmic ratio, but typically were $25 \mu \mathrm{m}$ in diameter with an irregular nucleus containing multiple small nucleoli. The cytoplasm was fairly profuse and foamy, staining grey-blue. A few of them were phagocytic to debris. Acid phosphatase staining was not done in this case.

In both cases the cytoplasm contained fat and some granular PAS-positive material

HODGKIN'S DISEASE

There were 13 cases of Hodgkin's disease. The breakdown of these is as follows:

Lymphocytic predominance 4 ; nodular sclerosing 4; mixed cellularity 3 : lymphocyte depleted 2 .

There were six men and seven women among the cases of Hodgkin's disease, and they ranged in age from 18 to $71 \mathrm{yr} ; 10$ had pleural effusion alone, one peritoneal alone, and two had both.

\section{Lymphocytic predominance}

Two patients had empyema, one due to Streptococcus faecalis (following a bowel perforation), and the other to a probable bronchopleural fistula. The later case showed some cells of Sternberg-Reed type among many pus cells.

Two patients had a mixed cellular picture in pleural fluid, with a predominance of macrophages. One showed no lymphoma cells, but the other had a few large "Hodgkin cells" in two successive pleural samples, as well as some eosinophils. A month later the cell picture had changed; there was a predominance of small lymphocytes together with cells looking like small centrocytes and "blast cells," and fairly frequent cells interpreted as Hodgkin cells; they were about $20 \mu \mathrm{m}$ in diameter, occupied mainly by a pale nucleus with fine chromatin and sometimes the outline of a nucleolus; the cytoplasm forming a moderately basophilic rim. There were also frequent eosinophils. No Sternberg-Reed cells were seen.
Nodular sclerosing

In all four pleural effusions the predominant cells were lymphocytes, and all had LP cells, macrophages and mesothelial cells present as well. Twc of them also contained a very few cells which might be Sternberg-Reed cells, but not definite enough for diagnosis; they were up to $30 \mu \mathrm{m}$ across, bilobed and without cytoplasmic vacuolation, and consequently did not resemble "lacunar cells."

\section{Mixed cellularity}

Of these three pleural effusions, none contained any recognisable lymphoma cells. All showed a mixed cell picture with lymphocytes, mesothelial cells, macrophages, and neutrophils.

\section{Lymphocyte depleted}

Of two cases, one had no recognisable lymphoma cells in two separate samples of pleural fluid. The other, a woman of $63 \mathrm{yr}$, had clearly neoplastic cells in pericardial as well as pleural effusions.

The pericardial fluid contained abundant eosinophils, together with lymphoma cells varying in diameter from $16 \mu \mathrm{m}$ up to $50 \mu \mathrm{m}$ in the large Sternberg-Reed types. The majority measured about $25 \mu \mathrm{m}$, with an oval nucleus showing fine or spongy chromatin, and a very large nucleolus - for example, $10 \mu \mathrm{m}$ across. The cytoplasm was fairly profuse, slightly to deeply basophilic and without any pale Golgi area. The Sternberg-Reed cells were of the above type, but with divided nuclei showing a mirror-image or butterfly configuration (Plate IIId).

The pleural fluid contained numerous similar cells, associated with macrophages, lymphocytes, neutrophils, and a few mesothelial cells and eosinophils.

\footnotetext{
"FALSE POSITIVE",
}

In the 30-year period covered, there was only one case in which lymphoma was diagnosed on cytological grounds, but in which confirmation was lacking and the patient recovered. This case has been briefly described and illustrated. ${ }^{5}$ The patient was an 80-year-old woman with a pleural effusion which did not recur after two aspirations, and required no other treatment. When she died 5 years later, necropsy showed no evidence of lymphoma or other malignant disease. On review, the slides would still be reported to show a high-grade malignant lymphoma; there was an almost uniform population of abnormal lymphoid cells resembling those described from Burkitt's lymphoma, ${ }^{15}$ together with pyknotic remains of cells as seen frequently in highgrade lymphomas. Two samples showed this picture twelve days apart. This might be an example of spontaneous regression, as it is difficult to think of another rational explanation. 


\section{Discussion}

Previous authors writing about lymphoma cells in serous effusions have belonged to one of three different schools, each with its own methodology. First there are those who have used only the histological method, and have examined sections of cell-blocks made from fluid deposit. ${ }^{20-23}$ Others have seen this as an extension of the cytological study of blood, marrow, and puncture material from lymph nodes and spleen. They have used dried smears fixed and stained with Giemsa or its analogues. ${ }^{519}$ Finally, the influence of Papanicolaou after the second world war led to the development of a whole speciality of "exfoliative cytology," almost exclusively using wet-fixed smears stained with haematoxylin and Papanicolaou's counterstains, and this method has been applied to the identification of lymphoma cells in effusions. ${ }^{18}{ }^{24-26}$ Eosin has sometimes been used as an alternative cytoplasmic stain. ${ }^{27}$

The lymphoma cells occurring in effusions are, of course, the same as those which would be found in the same case in lymph node imprints or punctures, and sometimes in bone marrow and blood. Even for these it is impossible to refer to any single work since the early sixties, offering a comprehensive correlation between cytology and histology. Jllustrations are scattered through various books and papers. ${ }^{2} 15$ 28-36

The names given to the different cell types in all of the currently recognised classifications are those used, and often introduced, by histopathologists, and the corresponding cells as seen in smears have in many cases not been clearly defined. There is a further difficulty inherent in the very nature of malignant disease, that each individual neoplasm appears to be unique. The cells in any given case differ among themselves "like the leaves on a tree" (Lewis), ${ }^{37}$ but all have a family resemblance specific to that clone. They can be rationally classified according to the degree and direction in which they tend to differentiate, as shown by simple morphology or by various histochemical or immunological tests; but it is not to be expected that they will fall into exact categories like postage stamps.

The cytopathologist is faced in practice with two questions before the classification of lymphomas ever arises. Firstly, are the cells in question benign lymphoid cells, and not neoplastic at all? Secondly, if the cells are neoplastic, are they from a lymphoma or from some other neoplastic condition (carcinoma, sarcoma, melanoma etc)?

BENIGN LYMPHOID CELLS $v$ LYMPHOMA First, the cytopathologist has to be familiar with the

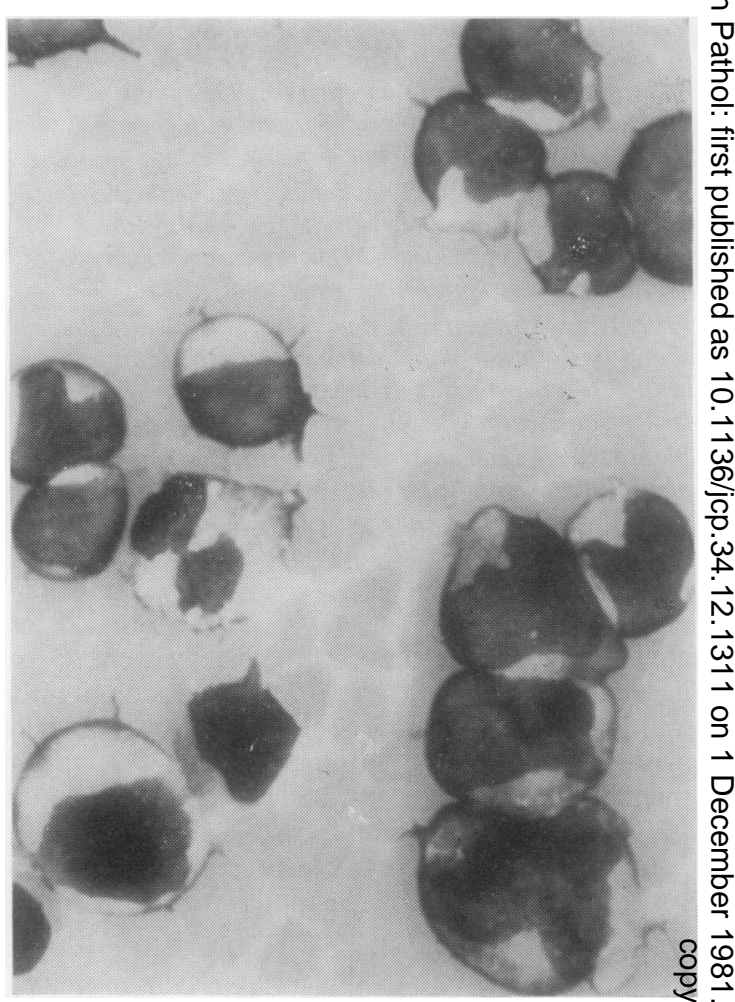

Fig. 4 Infectious mononucleosis. Cells in the deposit from peritoneal fluid aspirated during laparoscopy. May-Grünwald-Giemsa $\times 650$.

various appearances of reacting lymphoid cells such $\overrightarrow{\overrightarrow{0}}$ as LP cells and immunoblasts. Apart from serous fluids, it is helpful to have experience of the cells found in blood smears in viral infections and in. allergic reactions. Another excellent source of human lymphoid cells is the cerebrospinal fluid in viral meningitis.

Stimulated lymphoid cells seldom account for more than $10 \%$ of the population in benign serous 3 fluids. Hence neoplasia may be strongly suspectedo if such cells account for a majority of the cells present. A rare exception to this was seen in a case of infectious mononucleosis with a peritoneal effusion. The patient was a woman of $27 \mathrm{yr}$, presenting with abdominal pain attributed to endometriosis. Peri- $N$ toneal fluid was aspirated during laparoscopy, and about $90 \%$ of the cells present were atypical lympho- $\omega$ cytes ("glandular fever cells") with frequent mitotic figures. The diagnosis was confirmed by bloode

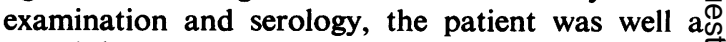
month later, and there has been no relapse. (Fig. 4).

Transformed B cells are not uncommon in serous 
fluids, and when they are numerous they normally show striking mitotic activity. This is not a criterion of malignancy. If adequate direct chromosomal preparations can be made, this can provide objective evidence whether the dividing cells are malignant or not; cells with normal karyotypes are most probably benign, and a clone with an abnormal karyotype is, in this context, presumed to be malignant. This method is inapplicable if the cells are not dividing; in chronic lymphocytic leukaemia for instance, spontaneous mitosis is not seen in the "small lymphocytes," and they do not respond to PHA. (This fact has even been used to distinguish them from normal lymphocytes. $)^{38}$

Benign-looking stimulated lymphoid cells are a common feature of effusions in Hodgkin's disease, and recognisable neoplastic cells were only found in a minority of our series (although Šimeček ${ }^{39}$ saw neoplastic cells in 14 of 23 effusions).

Most cytogenetic studies on lymph nodes in Hodgkin's disease support the concept that the Sternberg-Reed cells and mononuclear "Hodgkin cells" are neoplastic, and that the other leucocytes are reactive. The morphology of the cells in effusions suggests this too. However, there is some evidence that this impression may not be correct. Hossfeld and $\mathrm{Schmidt}^{40}$ made direct chromosome preparations from six effusions complicating Hodgkin's disease, of which only one contained identifiable Hodgkin cells or Sternberg-Reed cells; but all of them showed a majority of dividing cells to have grossly abnormal karyotypes, which were clearly clonal. One had a modal count of 60 , but the rest were near to diploid (45-48) with extensive rearrangements and markers. If the dividing cells in these cases were morphologically like benign LP cells (and this is not stated), the straightforward inference is that these form the neoplastic stemline in Hodgkin's disease.

All these were advanced cases which had been treated, and a conceivable alternative explanation is that cytotoxic treatment had resulted in the emergence of new abnormal clones (as occurs in the cases of iatrogenic leukaemia), but this is not the interpretation of the authors. This is an interesting area for further studies.

\section{LYMPHOMA $v$ CARCINOMA AND OTHER}

NEOPLASMS

Most cases of neoplastic effusion arise from epithelial tumours, and in these the malignant cells are usually coherent. Difficulty only arises when all the malignant cells are free, because lymphoma cells do not form cell to cell attachments.

In the occasional free-cell carcinoma, the distinction from lymphoma may arise. Round nuclei with one or two round nucleoli are in favour of carcinoma, while cleft or irregular nuclei with multiple irregular nucleoli favour lymphoma. Oat cells, when free and present in small numbers, may be very difficult to distinguish from malignant lymphoblasts or centrocytes. One looks for clusters, and even one such cluster with mutual nuclear moulding would rule out lymphoma. Free carcinoma cells sometimes show evidence of mucus secretion, or may show dense surface coverings of microvilli; both of these rule out lymphoma.

Sarcomas are nearly always distinguished by the clinical history. Amelanotic melanoma has occasionally been a problem, but these cells usually have a very large round nucleolus, which would be most uncommon in a lymphoma cell.

The presence of large numbers of dead tumour cells showing pyknosis and karyorrhexis is strong evidence of malignant lymphoma rather than any other type of neoplasm. ${ }^{26}$

\section{CYTOLOGICAL IDENTIFICATION OF}

SEPARATE LYMPHOMA TYPES

The subdivisions used here are believed to have a basis in reality, in that they represent neoplasms which are separable by immunological or histochemical methods, or both. However, the necessary battery of tests (including those on cells in suspension) was not applied to the cases in this series, and the diagnosis has been made on histological morphology backed up in some cases by immunoperoxidase staining. Quite apart from the limitations resulting from this indirect identification, nobody would claim at the present time that lymphoma cells in every case can be fitted into existing classifications, even using all the techniques currently available. Additional evidence from tissue architecture and cell distribution is certainly required, and even then there may be disagreement about the histological classification. We would not therefore suggest that a diagnosis of lymphoma type can regularly be made on cytological evidence alone.

Having said this, we do claim that with few exceptions the cytological picture has fitted well with the histological one, and that a cytological report on a lymphoma effusion can reasonably include a provisional opinion as to the grade of lymphoma (high or low) and a suggestion as to the direction of differentiation ("cell of origin").

Well differentiated lymphomas of lymphocytic, immunocytic, and plasmacytic types can be readily distinguished, provided that one can be confident that the relevant cells are neoplastic at all. Follicular lymphomas of centroblastic/centrocytic type sometimes show a characteristic picture, depending on the presence of neoplastic centrocytes with enough 
distinctive features to separate them from small lymphocytes; the diagnosis is made easier if some centroblasts are present too. Centrocytic lymphoma can only be separately distinguished if there is a rather uniform population of centrocytes, and this is most likely to be associated with a leukaemic picture. Of the high-grade lymphomas, centroblastic and immunoblastic lymphomas consist of relatively large cells, but are probably not separable from each other except in cases of immunoblastic lymphoma with some differentiation towards the plasma cell. Lymphoblastic lymphomas are separable as a group, provided that the neoplastic cells are in the lower part of their size range. The $T$ lymphoblastic lymphomas are histochemically distinct. Malignant histiocytosis can be diagnosed if the cells are sufficiently differentiated to show phagocytosis, and to give reactions for lysosomal enzymes.

An effusion containing high-grade lymphoma cells sometimes supervenes in a case being treated as a low-grade lymphoma on the grounds of a previous biopsy, and in such cases the cytological finding provides essential supplementary evidence.

We are grateful to $\mathrm{Mr} \mathrm{MM}$ Boddington, who collaborated with Dr AI Spriggs during most of the period over which the cytological material was collected.

\section{References}

${ }^{1}$ Lennert K, Mohri N, Stein H, Kaiserling E. The histopathology of malignant lymphoma. Br J Haematol 1975;31suppl:193-203.

2 Lennert K. Malignant lymphomas other than Hodgkin's disease. Berlin: Springer, 1978.

${ }^{3} \mathrm{Li} \mathrm{CY}$, Yam LT, Lam KW. Acid phosphatase isoenzyme in human leukocytes in normal and pathologic conditions. J Histochem Cytochem 1970;18:473-81.

4 Strunge T. La ponction des ganglions lymphatiques. Copenhagen: Munksgaard, 1944.

${ }^{5}$ Spriggs AI, Boddington MM. The cytology of effusions, pleural, pericardial and peritoneal, and of cerebrospinal fluid. 2nd ed. London: W Heinemann, 1968.

- Moeschlin S. Phasenkontrastuntersuchungen in der Hämatologie. Acta Haematol (Basel) 1949;2:399-426.

? Rosenthal N, Dreskin OH, Vural IL, Zak FG. The significance of hematogones in blood, bone marrow and lymph node aspiration in giant follicular lymphoblastoma. Acta Haematol (Basel) 1952 ;8:368-77.

8 McKenna RW, Bloomfield CD, Brunning RD. Nodular lymphoma: bone marrow and blood manifestations. Cancer $1975 ; 36: 428-40$.

- Murad TM. Electron microscopic studies of cells in pleural and peritoneal effusions. Acta Cytol 1973;17:401-9.

${ }^{10}$ Hajdu SI, Hajdu EO. Cytopathology of sarcomas and other nonepithelial malignant tumors. Philadelphia: Saunders, 1976.

11 Humble JG, Jayne WHW, Pulvertaft RJV. Biological interaction between lymphocytes and other cells. $B r J$ Haematol 1956;2:283-94.
12 Ioachim H, Furth J. Intrareticular cell multiplication of leukemic lymphoblasts in thymic tissue cultures. $J$ Natl Cancer Inst 1964;32:339-59.

${ }^{13}$ Lipsky PE, Rosenthal AS. Macrophage-lymphocyte $\Rightarrow$ interaction. I Characteristics of the antigen-independent $\mathscr{S}$ binding of guinea pig thymocytes to syngeneic macro- $\overline{0}$ phages. J Exp Med 1973;138:900-24.

${ }^{14}$ Rosai J, Dorfman RF. Sinus histiocytosis with massive lymphadenopathy: a pseudolymphomatous benign disorder. Cancer 1972;30:1174-88.

${ }^{15}$ Berard C, O'Conor GT, Thomas LB, Torloni H. Histopathological definition of Burkitt's tumour. Bull WHO 1969;40:601-7.

16 Catovsky D, Galetto J, Okos A, Miliani E, Galton DAG. Cytochemical profile of B and T leukaemic lymphocytes with special reference to acute lymphoblastic leukaemia. J Clin Pathol 1974;27:767-71.

${ }^{17}$ McKenna RW, Brynes RK, Nesbit ME et al. Cytochemical profiles in acute lymphoblastic leukemia. Am J Pediat Hematol/Oncol 1979;1:263-75.

18 Melamed MR. The cytological presentation of malignant $\vec{N}$ lymphomas and related diseases in effusions. Cancer $1963 ; 16: 413-31$.

19 Lopes Cardozo P. Atlas of clinical cytology. s'Hertogenbosch: Lopes Cardozo, nd, 1976.

20 Wihman G. A contribution to the knowledge of the cellular content in exudates and transudates. Acta Med Scand 1948 ;suppl 205.

${ }^{21}$ Dawe CJ, Woolner LB, Parkhill EM, McDonald JR. Ф Cytologic studies of sputum, secretions and serous 3 fluids in malignant lymphoma. Am J Clin Pathol 1955; 25:480-8.

${ }^{22}$ Luse SA, Reagan JW. A histocytological study of effusiong II Effusions associated with malignant tumors. Cance $\infty$ $1954 ; 7: 1167-81$

${ }^{23}$ Luse SA, Reagan JW. A histocytologic and electrof microscopic study of effusions associated with malignant disease. Ann NY Acad Sci 1955-6;63:1331-47.

24 Johnson WD. The cytological diagnosis of cancer in serous effusions. Acta Cytol 1966;10:161-72.

${ }^{25}$ Billingham ME, Rawlinson DG, Berry PF, Kempson RL. The cytodiagnosis of malignant lymphomas and Hodgkin's disease in cerebrospinal, pleural and ascitic fluids. Acta Cytol 1975;19:547-56.

${ }^{28}$ Koss L. Diagnostic cytology and its histopathologic bases. 3rd ed. Philadelphia: Lippincott, 1979.

27 Woyke S, Domagała W. Cytological evaluation of fluids from body cavities. III Malignant lymphoma cells (in Polish). Nowotwory $1971 ; 21: 31-6$.

28 Lennert $\mathrm{K}$. Über die Erkennung von Keimzentrumszellen im Lymphknotenausstrich. Klin Wochenschr 1957;35 1130-2.

${ }^{29}$ Leiber B. Der menschliche Lymphknoten. Munich: Urban \& Schwarzenberg, 1961.

${ }^{30}$ Lennert K. Lymphknoten. Diagnostik in Schnitt und Ausstrich. In: Lubarsch O, Henke F, Rössle R, Uehlinger E, eds. Handbuch der speziellen pathologischen Anatomie und Histologie. Vol A1, part 3. Berlin: Springer, 1961.

${ }^{31}$ Mathé G, Seman G. Aspects histologiques et cytologiques des leucémies et hématosarcomes. Paris: Maloine, 1963.

${ }^{32}$ Dick F, Bloomfield CD, Brunning RD. Incidence, cytology and histopathology of non-Hodgkin's lymphomas in the bone marrow. Cancer 1974; 33:1382-98.

${ }^{33}$ Mathé G, Pouillart P, Schlumberger JR, Paintrand M. Cytology in the classification of diffuse non-leukaemic malignant lymphomata (lympho-and reticulosarcomata). Br J Cancer 1975;31suppl II :53-9.

${ }^{34}$ Pinkel D, Johnson W, Aur RJA. Non-Hodgkins lymphoma in children. Br J Cancer 1975; 31 suppl. II : 298-323.

\section{.}


${ }^{35}$ Rilke F, Pilotti S, Carbone A, Lombardi L. Morphology of lymphatic cells and of their derived tumours. J Clin Pathol 1978;31:1009-56.

${ }^{36}$ Feinberg MR, Bhaskar AG, Bourne P. Differential diagnosis of malignant lymphomas by imprint cytology. Acta Cytol 1980;24:16-25.

${ }^{37}$ Lewis WH. Malignant cells. Harvey lectures, 16 April 1936:214-34.

${ }^{38}$ Boccato P, Saran B, Pasini L, Pasini P. Immunology of lymphocytes in pleurisy and in effusions due to pleural infiltration by chronic lymphocytic leukemia cells.
Acta Cytol 1978;22:284-5.

${ }^{39}$ Simeček C. Zytologie der Pleuraergüsse bei den Sarkomen des lymphoretikulären Gewebes. Arch Geschwulstforsch 1977; 47:197-203.

${ }^{40}$ Hossfeld DK, Schmidt CG. Chromosome findings in effusions from patients with Hodgkin's disease. Int J Cancer $1978 ; 21: 147-56$.

Requests for reprints to: Dr AI Spriggs, Laboratory of Clinical Cytology, The Churchill Hospital, Headington. Oxford OX3 7LJ, England. 